\title{
HLA-B*35 as a new marker for susceptibility to human T-cell lymphotropic virus type 1 (HTLV-1) Associated Myelopathy/Tropical
} Spastic Paraparesis (HAM/TSP) in patients living in Argentina

Paula Benencio ${ }^{1}$, Sindy A. Fraile Gonzalez ${ }^{1}$, Nicolás Ducasa ${ }^{1}$, Kimberly Page ${ }^{2,3}$, Carolina A. Berini ${ }^{1{ }^{*+}}$ and Mirna M. Biglione ${ }^{1 \dagger}$

\begin{abstract}
Background: Human T-cell lymphotropic virus type 1 (HTLV-1) is the etiological agent of HTLV associated myelopathy/ Tropical Spastic Paraparesis (HAM/TSP) and Adult T cell leukemia/lymphoma (ATLL), in around 2-5\% of the infected individuals. Host genetic background might play a role in disease progression. Several previous studies across many countries report HLA haplotype to be one such factor. Here, we sequenced HLA-A, -B and -C of 66 individuals by Sequence-Based Typing (SBT), and compared the frequency of different alleles among ATLL patients, HAM/TSP patients, asymptomatic carriers and non-infected individuals living in Argentina.

Results: The frequency of HLA-A, $-B$ and $-C$ alleles largely matched that of the general population in Argentina. We identified HLA-A*02, HLA-B*35 and HLA-C*07 as associated to protection from ATLL ( $p=0.031$ ), susceptibility to HAM) $\operatorname{TSP}(p<0.001)$ and susceptibility to ATLL $(p=0.017)$, respectively. We also found a strong correlation between high proviral load $(\mathrm{PVL})$ and disease $(p=0.008)$, but were unable to identify any particular allele associated with high or low PVL.

Conclusions: We have found HLA-A*02, HLA-B*35 and HLA-C*07 to be associated to protection from ATLL (HLA$A^{*} 02$ ) and susceptibility to HAM/TSP (HLA-B*35) or to ATLL (HLA-C $\left.C^{*} 07\right)$, respectively. Whereas HLA-A*02 protection from ATLL has already been extensively described in other regions of the world, this is the first report that links HLA$\mathrm{B}^{*} 35$ and an increased susceptibility to HAM/TSP. As for HLA-C*07 it has previously been associated to susceptibility to HAM/TSP in other countries but in our population it has been linked to ATLL.
\end{abstract}

Keywords: HTLV-1, HAM/TSP, ATLL, PVL, HLA, ARGENTINA

*Correspondence: cberini@fmed.uba.ar

${ }^{\dagger}$ Carolina A. Berini and Mirna M. Biglione contributed equally to this work ${ }^{1}$ CONICET- Universidad de Buenos Aires, Instituto de Investigaciones Biomédicas en Retrovirus y SIDA (INBIRS), Paraguay 2155, C1121ABG Ciudad Autónoma de Buenos Aires, Argentina Full list of author information is available at the end of the article

\section{Background}

Human T-cell lymphotropic virus type 1 (HTLV-1) was the first human retrovirus to be discovered and is the etiological agent of Adult $\mathrm{T}$ Cell Leukemia/Lymphoma (ATLL), a progressive neurological disease called HTLV-1 Associated Myelopathy/Tropical Spastic Paraparesis (HAM/TSP) $[1,2]$, Uveitis, a severity factor for Bronchiectasis and other diseases [3]. In Argentina, the 
Northwestern region (Salta and Jujuy provinces) is considered endemic for HTLV-1 infection [4].

The vast majority of HTLV-1-infected individuals are asymptomatic and around 1-2\% of them will develop ATLL and less than 5\%, HAM/TSP. Although the risk factors causing different HTLV-1 associated diseases are not fully understood, their pathogenesis is thought to be in part due to proviral load (PVL) and/or the host genetic factors [5-7].

The target cells of HTLV-1 are CD4 ${ }^{+} \mathrm{T}$ cells, and to a lesser extent $\mathrm{CD} 8+\mathrm{T}$ cells, B cells, monocytes, macrophages and dendritic cells [7]. The maintenance of HTLV-1 infection occurs mostly by clonal expansion of infected cells. In the case of ATLL, the expression of Tax protein in some of these clones with accumulated genomic abnormalities could help develop a pre-leukemic state in some individuals. The malignantly transformed HTLV-1 infected cells very often suppress Tax expression in favor of HTLV-1 basic leucine zipper factor (HBZ) expression, a negative regulator of Tax that is believed to aid immune evasion of the infected cells and further assist cancerous transformation [8]. On the other hand, the increased number of HTLV-1 infected T-cells may also cause imbalance of the immune system, resulting in immune dysfunction or inflammatory diseases like myelopathy and uveitis [9]. In this context, HAM/TSP pathogenesis is a hyperactive immune response induced by HTLV-1 infection that produces chronic inflammation in the central nervous system (CNS) with slowly progressive evolution. It is characterized by the production of elevated levels of proinflammatory cytokines, including IFN-y and TNF, and by HTLV-1-specific CD8 ${ }^{+}$T cells in peripheral blood and spinal cord lesions [10-12].

Human Leukocyte Antigen (HLA) class I genes have been associated with susceptibility to disease in many human infections and it is among the host genetic factors that could be related to manifestation of ATLL and HAM/TSP [13, 14]. A unifying theory is that HLA alleles associated with ATLL show a limited recognition of HTLV-1 Tax peptide anchor motifs and epitopes capable of generating anti-HTLV-1 Tax $\mathrm{CD}^{+} \mathrm{T}$ cells while for HAM/TSP they induce strong cytotoxic T-lymphocyte (CTL) responses against the viral oncoprotein Tax $[15$, 16].

Specific HLA alleles have been linked to protection from developing these pathologies, whereas other HLA alleles have been correlated with an increased risk of developing them (Table 1). Some studies reported the HLA-A*02 allele to have a protective role both in ATLL and HAM/TSP disease in Jamaica, Brazil, Japan and Peru [16-21]. The same was the case for allele HLA-Cw*08 in Japan and Iran [16, 20, 22]. HLA-A*26 and A*54 were associated with susceptibility to ATLL and HAM/TSP, respectively, in Japan, whereas $A * 36$ was associated with susceptibility to ATLL in Jamaica [17, 23]. In contrast, HLA-B*5401 has been associated with an increased susceptibility to HAM/TSP in Japan and Iran [16, 24]. Allele C*07, on the other hand, has been associated to susceptibility to disease in Brazil, only in patients who did not possess A*02 [25].

Another perspective suggests that greater HLA diversity conveys selective advantage against disease because the immune response is elicited by a greater variety of antigens as described for human immunodeficiency virus (HIV) and acquired immunodeficiency syndrome (AIDS) [26]. Since each HLA allele exposes a different set of amino acids in their peptide cleft, they will each be able to present peptides with different specificities. This results in a heterogeneous capacity to activate $\mathrm{T}$ $\mathrm{CD}^{+}$lymphocytes to target the infected cells. Carrying mismatched alleles for each HLA gene thus confers the ability to present a wider range of peptides, and to then be more likely to activate cytotoxic $\mathrm{T}$ cells to eliminate infected cells. It has been reported that, in HIV infection, HLA class I heterozygotes progress more slowly to AIDS than do homozygotes and that the viral load is significantly lower due to rare HLA class I alleles [27]. In relation to HTLV-1 infection, Goedert et al. showed that HLA class I diversity reduces the risk of ATLL presumably by limiting the proliferation of HTLV-1 infected cells in vivo and therefore decreasing the possibilities of developing the disease [28].

The aim of this study was to identify HLA class I alleles associated to protection or susceptibility to disease and to analyze its possible association with proviral load in individuals infected with HTLV-1 living in Argentina.

\section{Methods}

Peripheral blood samples were obtained from a total of 66 individuals, of which 52 presented HTLV-1 infection (9 ATLL, $22 \mathrm{HAM} / \mathrm{TSP}, 21$ asymptomatic carriers (AC)) and 14 non-infected individuals (NII). All of them attended our Institute seeking HTLV-1/2 diagnosis between 2003 and 2018 .

The protocol was reviewed and approved by the Institutional Review Board as well as by the External Ethical Committee (NEXO AC IRB\#0005349, protocol \#1563). An informed consent was obtained from all individuals. The diagnosis of ATLL and HAM/TSP was performed in accordance with Tsukasaki and Osame criteria, respectively [29]. Peripheral blood mononuclear cells (PBMCs) were isolated from EDTA-treated blood samples by a Ficoll-Hypaque density gradient (Ficoll Paque Plus, Sigma Aldrich, Saint Louis, USA) and DNA was extracted using a commercial kit (ADN PuriPrep-S kit, Inbio Highway, Tandil, Argentina). After serological screening, HTLV-1 
Table 1 Alleles previously associated with either protection or susceptibility to HTLV-1 associated diseases

\begin{tabular}{|c|c|c|c|}
\hline $\begin{array}{l}\text { Country/Continent } \\
\text { (Reference) }\end{array}$ & N, Population & Protective allele & Detrimental allele \\
\hline Africa [52] & $\begin{array}{l}N=45, A c \\
N=49, A T L L \\
N=51, N \|\end{array}$ & - & $\begin{array}{l}\text { HLA-A*36 } \\
\text { HLA-B*18 }\end{array}$ \\
\hline \multirow[t]{2}{*}{ Brazil $[18,19]$} & $\begin{array}{l}N=71, \mathrm{HTLV}-1+ \\
N=188, \mathrm{NII}\end{array}$ & HLA-A*02 (HAM) & HLA-A*26 (ATLL) \\
\hline & $\begin{array}{l}N=53, A C \\
N=55, \text { HAM }\end{array}$ & HLA-A*02 & - \\
\hline Spain [14] & $\begin{array}{l}N=40, A C \\
N=20, H A M\end{array}$ & - & $\begin{array}{l}\text { HLA-B*5401 absent } \\
\text { HLA-B*07 }\end{array}$ \\
\hline \multirow[t]{3}{*}{ Iran $[22,24,49]$} & $\begin{array}{l}N=74, A C \\
N=58, H A M\end{array}$ & - & HLA-B*5401 \\
\hline & $\begin{array}{l}\text { Iranian } \\
N=74, \text { Ac } \\
N=58, \text { HAM } \\
\text { Kagoshima } \\
N=184, \text { AC } \\
N=222, \text { HAM }\end{array}$ & $\mathrm{HLA}-\mathrm{CW}^{*} 08$ & - \\
\hline & $\begin{array}{l}N=20, \mathrm{HAM} \\
N=30, A C\end{array}$ & $\begin{array}{l}\text { No association: } \\
\text { HLA-A*02 } \\
\text { HLA-A*24 } \\
\text { HLA-CW*08 }\end{array}$ & - \\
\hline \multirow[t]{2}{*}{ Jamaica $[17,28]$} & $\begin{array}{l}N=45, A C \\
N=25, A T L L\end{array}$ & $\begin{array}{l}\text { HLA-A*02 } \\
\text { HLA-A } 333\end{array}$ & $\begin{array}{l}\text { HLA-A*03 } \\
\text { HLA-A*36 }\end{array}$ \\
\hline & $\begin{array}{l}N=56, A T L L \\
N=59, H A M\end{array}$ & $H L A-A^{*} 03$ & $\begin{array}{l}\text { HLA-B*15 } \\
\text { HLA-B* } 53\end{array}$ \\
\hline \multirow[t]{4}{*}{ Japan $[16,20,23,53]$} & $\begin{array}{l}N=34, A T L L \\
N=55, H A M \\
N=241, A C\end{array}$ & - & $\begin{array}{l}\text { HLA-A*26 (ATLL) } \\
\text { HLA-B*61 (ATLL) } \\
\text { HLA-B*07 (HAM) } \\
\text { HLA-CW*07 (HAM) }\end{array}$ \\
\hline & $\begin{array}{l}N=175, \mathrm{NII} \\
N=152, \mathrm{AC} \\
\mathrm{N}=124, \mathrm{ATLL} \\
\mathrm{N}=148, \mathrm{HAM}\end{array}$ & - & $\begin{array}{l}\text { HLA-A*26 } \\
\text { HLA-B*4002 } \\
\text { HLA-B*4006 } \\
\text { HLA-B } 4801\end{array}$ \\
\hline & $\begin{array}{l}N=233, \text { HAM } \\
N=202, \mathrm{NII}\end{array}$ & $\begin{array}{l}\text { HLA-A*02 } \\
\text { HLA-CW*08 }\end{array}$ & HLA-B*5401 \\
\hline & $\begin{array}{l}N=201, A C \\
N=232, \text { HAM }\end{array}$ & $\begin{array}{l}\text { HLA-A*0201 } \\
\text { HLA-CW*0801 }\end{array}$ & HLA-B*5401 \\
\hline Peru [21] & $\begin{array}{l}N=71, \mathrm{HAM} \\
N=94, \mathrm{AC}\end{array}$ & HLA-A*02 & - \\
\hline
\end{tabular}

Ac asymptomatic carriers, HAM/TSP HTLV-1 associated myelopathy/Tropical Spastic Paraparesis, ATLL Adult T cell leukemia/lymphoma, NII Non-infected Individuals, HLA Human leukocyte antigen

infection was confirmed by an in-house nested polymerase chain reaction (n-PCR) as described elsewhere [30]. Absolute quantitation of PVL was performed by real-time SYBR Green PCR, using an ABI Prism 7500 Prism System (Applied Biosystems, USA) as previously described [31, 32].

HLA class I characterization was performed by sequence based typing (SBT). HLA-A exons 2 and 3 were amplified together while HLA-B/C exons 2 and 3 were amplified separately, as described elsewhere [33].

Amplicons were sequenced using the Big Dye Terminator sequencing kit (Applied Biosystems, USA) on a 3500xL Genetic Analyzer AB/HITACHI according to the manufacturer's instructions.

For the calculation of allele frequencies, we counted each individual allele for each locus across all samples. In the cases where an individual resulted homozygous for a locus, this situation was equivalent to a count of 2 for the corresponding allele.

For the analysis of homozygosis/ heterozygosis, we excluded from the total count those individuals whose haplotypes could not be typed, or were partially elucidated. 
Data analysis was performed using the Kruskal-Wallis non-parametric method; when two groups were compared the $\mathrm{Chi}^{2}$ test or Exact Fisher test, and one-way ANOVA were used. Epidat (version 4.2) and GraphPad Prism (version 6.03) software was applied and significant differences were defined as $p<0.05$.

\section{Results}

We analyzed a total of in 66 individuals living in Argentina of whom 16 were born in other South American countries such as Paraguay $(6.1 \%, \mathrm{n}=4)$ and Peru $(18.2 \%$, $\mathrm{n}=12$ ). Among the 66 samples analyzed, there was no significant difference in biological sex $(p=0.410$, Table 2$)$ between asymptomatics and the group with HTLV-1 associated pathologies. On the other hand, there was a significant difference in age $(p=0.002$, mean age $=41.05$, mean age $\mathrm{NII}=32.27$, mean age $\mathrm{AC}=38.6$, mean age $\mathrm{HAM} / \mathrm{TSP}=46.57$, mean age ATLL $=44.33$, Table 2) when analyzing the same groups. Table 2 presents the demographic characteristics of all studied individuals. None of the Argentine individuals reported being born nor have they been derived from endemic areas for HTLV-1 infection in the country.

Out of the 66 samples included in the study, a total of 53 were typed for HLA-A (13 NII, 17 AC, 7 ATLL, 16 HAM/TSP), 61 for HLA-B (14 NII, 19 AC, 7 ATLL, 21 HAM/TSP) and 38 of them were analyzed for HLA-C (14 NII, 18 AC, 3 ATLL, 3 HAM/TSP). There were also a total of 14 samples for which only one of the alleles for a specific HLA I loci could be identified. Therefore, a total of 103 alleles could be typed for HLA-A, 112 for HLA-B and 74 for HLA-C.

Overall, $\mathrm{A} * 02$ (36.89\%), B*35 (25.00\%) and $\mathrm{C} * 07$ (33.78\%) were the most frequent in the population studied. Tables 3, 4 and 5 shows the frequencies of individual alleles in all the studied individuals.

In relation to HLA-A, the alleles $\mathrm{A} * 23, \mathrm{~A} * 24, \mathrm{~A} * 32$ and $A * 68$ were observed among ATLL patients, but not in HAM/TSP, while the opposite case was found for $A^{*} 11$ and $A^{*} 29$ in HAM/TSP patients but not ATLL. There was a significant difference in the frequency of HLA-A*02 between asymptomatic carriers and those with ATLL $(p=0.031)$ (Table 3, Fig. 2). Allele $\mathrm{A} * 01$ was only found among NII; $\mathrm{A}^{*} 25$ and $\mathrm{A} * 26$, among $\mathrm{AC} ; \mathrm{A}^{*} 11$, among HAM/TSP patients; and $A * 23$ and $A * 32$ among ATLL patients.

For HLA-B, the alleles HLA-B*27 and $B * 40$ were only found in NII; $B * 48$ and $B * 53$, only in $A C ; B^{*} 18$, in ATLL; and $B * 13, B * 15, B * 41, B * 49$ and $B * 55$, in HAM/ TSP individuals. Nevertheless, these alleles were too rare to draw any conclusions from these findings. The allele B*35 was significantly more frequent among the patients with HAM/TSP compared to asymptomatic carriers $(p<0,001)$ (Table 4, Fig. 2).

For the 38 HLA-C samples, the alleles $C^{*} 01$ and $C^{*} 31$ were only found in NII, while the alleles $C^{*} 05, C^{*} 06$, C*16 and C*18 were exclusive for asymptomatic carriers. There were not any ATLL- or HAM-exclusive alleles. Overall, patients that had developed either one of the associated pathologies exhibited a rather limited arrange of alleles: only $C * 03, C * 07$ and $C * 15$ were identified in our analysis. Out of the 3 pathology cases (1 HAM/TSP and 2 ATLL) that presented $C^{*} 07$, all of them were homozygotes for that loci and none displayed the allele $\mathrm{A}^{*} 02$. In the $\mathrm{AC}$ group, 4 individuals presented $C^{*} 07$ (3 in homocigosis), and one individual was homozygous for $\mathrm{A}^{* 02}$ (Fig. 1c, Table 5, Fig. 2). The allele HLA-C*07 was significantly higher among ATLL individuals $(p=0.017)$ compared to $\mathrm{AC}$, but not among HAM/TSP patients $(p=0.466)$.

We repeated the analysis taking in consideration the Argentine individuals only $(n=50)$, the results showed differences in HLA-A*02, being significantly more frequent in AC than in ATLL $(p=0.025)$; and in HLA-C*07 which did not exhibit any difference among the studied groups. HLA-B*35 was not found in AC, whereas it was present in 12 out of 33 alleles for HAM/ TSP and 3 out of 13 for ATLL.

The mean PVL in asymptomatic carriers was 2.78 per 100 PBMCs, and 10.44 in individuals with HTLV-1 associated pathologies (16.36 for ATLL and 8.56 for HAM/TSP patients). PVL of patients with HTLV-1 associated pathologies was significantly higher than that of asymptomatic carriers $(p=0.008$, Tables 6 , 7 and 8) while there were no differences between the mean PVL of ATLL and HAM/TSP patients $(p=0.165$, Tables 6,7 and 8 ). Table 6,7 and 8 presents the values of PVL classified per HLA-A, HLA-B and HLA-C alleles. No significant differences were observed for HLA-A, B and C when comparing the PVL among all the alleles of each loci by one-way ANOVA.

Most of the ATLL and HAM/TSP patients were homozygous for HLA-A (20/21) locus, in contrast to the HLA-B locus (4/21). Regarding heterozygosity, for the HLA-A locus there was a significant difference when comparing asymptomatics versus individuals with pathologies, heterozygosity being more frequent among asymptomatics $(p=0.038$, Table 9$)$. Nevertheless, all of the individuals with ATLL were heterozygous for HLA-B.

We found all of the ATLL and HAM patients that could be typed for HLA-C to be homozygous for this gene and all of the asymptomatic carriers to be homozygous for HLA-B (Table 9). 
Table 2 Demographic characteristics of the studied population

\begin{tabular}{|c|c|c|c|c|c|c|}
\hline Code & Population & City/ Country of derivation & Birthplace & Biological sex & Age (years) & PVL \\
\hline 132,253 & $\mathrm{NII}$ & Buenos Aires Province & Buenos Aires Province & M & 31 & NA \\
\hline 132,254 & HAM & Buenos Aires Province & Buenos Aires Province & M & 50 & 1.35 \\
\hline 153,302 & $A C$ & Buenos Aires City & Buenos Aires City & $\mathrm{F}$ & 47 & ND \\
\hline 154,545 & $\mathrm{NII}$ & Buenos Aires City & Buenos Aires City & $\mathrm{F}$ & 22 & NA \\
\hline 201,437 & $A C$ & Buenos Aires City & Buenos Aires Province & M & 31 & 0.39 \\
\hline 203,568 & $A C$ & Buenos Aires City & Perú & $\mathrm{F}$ & 36 & 2.91 \\
\hline 203,835 & $A C$ & Buenos Aires City & Buenos Aires Province & M & 18 & 0,68 \\
\hline 325,784 & $\mathrm{NII}$ & Buenos Aires Province & Peru & $\mathrm{F}$ & 36 & NA \\
\hline 327,362 & $A C$ & Buenos Aires Province & Buenos Aires Province & M & 61 & 5.3 \\
\hline 327,557 & $A C$ & Buenos Aires Province & Buenos Aires Province & $\mathrm{F}$ & 42 & 11.83 \\
\hline $2,013,082$ & $\mathrm{NII}$ & Buenos Aires Province & Peru & $\mathrm{F}$ & 41 & NA \\
\hline $2,013,100$ & HAM & Buenos Aires City & Buenos Aires Province & M & 49 & 4.03 \\
\hline $2,013,102$ & $A C$ & Buenos Aires City & Buenos Aires Province & $\mathrm{F}$ & 36 & 0.29 \\
\hline $2,014,059$ & ATLL & Buenos Aires City & Entre Ríos & $\mathrm{F}$ & 62 & ND \\
\hline $2,014,090$ & $\mathrm{NII}$ & Buenos Aires City & Buenos Aires City & $\mathrm{F}$ & 38 & NA \\
\hline $2,014,101$ & $A C$ & Buenos Aires City & Buenos Aires City & M & 32 & 0.58 \\
\hline $2,014,102$ & $A C$ & Buenos Aires City & Paraguay & M & 56 & 1.29 \\
\hline $2,014,150$ & $A C$ & Buenos Aires Province & Peru & M & 34 & 4.61 \\
\hline $2,014,151=2,016,111$ & HAM & Buenos Aires Province & Peru & $\mathrm{F}$ & 61 & 12.86 \\
\hline $2,014,160$ & $A C$ & Buenos Aires City & Buenos Aires City & F & NA & 0,57 \\
\hline $2,014,161$ & $\mathrm{NII}$ & Buenos Aires City & Peru & M & NA & NA \\
\hline $2,015,014$ & $A C$ & Buenos Aires City & Paraguay & M & 34 & 1.12 \\
\hline $2,015,024$ & $A C$ & Buenos Aires City & Peru & $\mathrm{F}$ & 39 & 0,09 \\
\hline $2,015,025$ & $A C$ & Buenos Aires City & Peru & M & 43 & 2.51 \\
\hline $2,015,038$ & $\mathrm{NII}$ & Buenos Aires City & Paraguay & $\mathrm{F}$ & 38 & NA \\
\hline $2,015,059$ & $\mathrm{NII}$ & Santa Fe & Santa Fe & $\mathrm{F}$ & 23 & NA \\
\hline $2,015,062$ & $\mathrm{NII}$ & Santa Fe & Santa Fe & M & 20 & NA \\
\hline $2,015,074=2,017,009$ & $A C$ & Buenos Aires Province & Peru & $\mathrm{F}$ & 39 & 10.77 \\
\hline $2,015,082$ & $\mathrm{NII}$ & Buenos Aires City & Buenos Aires Province & $\mathrm{F}$ & 49 & NA \\
\hline $2,015,090$ & $A C$ & Buenos Aires City & Paraguay & $\mathrm{F}$ & 27 & 0.79 \\
\hline $2,015,106$ & HAM & Tucumán & Perú & $\mathrm{F}$ & 41 & 2.00 \\
\hline $2,015,107$ & ATLL & Buenos Aires City & Buenos Aires Province & M & 18 & 9.87 \\
\hline $2,015,116$ & $\mathrm{NII}$ & Buenos Aires City & Misiones & M & 30 & NA \\
\hline $2,016,001$ & $\mathrm{NII}$ & Buenos Aires City & Buenos Aires City & F & 27 & NA \\
\hline $2,016,002$ & $A C$ & Buenos Aires City & Buenos Aires City & M & 28 & 0.92 \\
\hline $2,016,010$ & HAM & Santa Fe & Santa Fe & $\mathrm{F}$ & 45 & 10.3 \\
\hline $2,016,049$ & $A C$ & Buenos Aires City & Peru & $\mathrm{F}$ & 47 & 0.19 \\
\hline $2,016,050$ & $A C$ & Buenos Aires City & Peru & M & 52 & 1.46 \\
\hline $2,016,065$ & $A C$ & Santa Fe & Santa Fe & M & 48 & 9.24 \\
\hline $2,016,066$ & $A C$ & Santa Fe & Santa Fe & M & 22 & 0.11 \\
\hline $20,110,055=20,110,063$ & ATLL & Buenos Aires City & Tucumán & $\mathrm{F}$ & 66 & 40.2 \\
\hline $20,110,057$ & $\mathrm{NII}$ & Buenos Aires City & Tucumán & $\mathrm{F}$ & NA & NA \\
\hline $20,110,059$ & $\mathrm{NII}$ & Buenos Aires City & Tucumán & M & NA & NA \\
\hline 44,971 & HAM & Buenos Aires City & NA & $\mathrm{F}$ & 25 & 3.12 \\
\hline 45,674 & HAM & NA & NA & $\mathrm{F}$ & 67 & 1.67 \\
\hline 46,793 & HAM & Buenos Aires Province & NA & NA & NA & ND \\
\hline 49,067 & HAM & NA & NA & M & 55 & 15.53 \\
\hline 138,398 & HAM & NA & NA & $\mathrm{F}$ & 56 & 29.54 \\
\hline 146,570 & HAM & Buenos Aires Province & NA & $\mathrm{F}$ & 51 & 4.78 \\
\hline
\end{tabular}


Table 2 (continued)

\begin{tabular}{|c|c|c|c|c|c|c|}
\hline Code & Population & City/ Country of derivation & Birthplace & Biological sex & Age (years) & PVL \\
\hline 170,313 & ATLL & Buenos Aires City & NA & $\mathrm{F}$ & 29 & ND \\
\hline 174,908 & HAM & Buenos Aires City & NA & M & 19 & 0.12 \\
\hline 180,405 & HAM & Buenos Aires City & NA & $\mathrm{F}$ & 71 & 10.45 \\
\hline 192,816 & HAM & Buenos Aires City & NA & $\mathrm{F}$ & 37 & ND \\
\hline 195,086 & ATLL & Buenos Aires City & NA & $\mathrm{F}$ & 48 & 1.30 \\
\hline 198,544 & ATLL & Buenos Aires City & NA & $\mathrm{F}$ & 67 & 12.49 \\
\hline 209,803 & HAM & Buenos Aires City & NA & $\mathrm{F}$ & 27 & 3.12 \\
\hline 228,185 & ATLL & Buenos Aires City & NA & M & 53 & 33.98 \\
\hline 244,886 & ATLL & Santa Fe & NA & M & 31 & ND \\
\hline 248,684 & HAM & Buenos Aires City & NA & M & 65 & 5.39 \\
\hline 255,404 & HAM & Buenos Aires City & NA & M & 31 & ND \\
\hline $20,110,028$ & HAM & Buenos Aires City & NA & $\mathrm{F}$ & 52 & 8.57 \\
\hline $2,012,028$ & HAM & Buenos Aires City & NA & M & 52 & 35.10 \\
\hline $2,012,135$ & ATLL & Buenos Aires City & NA & M & 25 & 0,34 \\
\hline $20,110,001$ & HAM & Buenos Aires City & NA & $\mathrm{F}$ & 43 & 0.71 \\
\hline $2,014,057$ & HAM & Buenos Aires City & NA & M & 41 & 13.09 \\
\hline $2,014,063$ & HAM & Tucumán & NA & $\mathrm{F}$ & 40 & 1.01 \\
\hline
\end{tabular}

NII Non-infected Individual, AC Asymptomatic Carrier, HAM HTLV-1 associated myelopathy, ATLL adult T cell leukemia/lymphoma, F Female, $M$ Male, PVL proviral load, $N A$ not available, $N D$ not determined

Table 3 Number and frequency of every HLA-A allele found in our population for each group

\begin{tabular}{|c|c|c|c|c|c|c|}
\hline \multirow[t]{2}{*}{ Allele } & \multicolumn{4}{|c|}{ Population } & \multirow[t]{2}{*}{ Overall } & \multirow[t]{2}{*}{ Allele frequency } \\
\hline & NII & $A C$ & ATLL & HAM & & \\
\hline HLA-A*01 & 4 & 0 & 0 & 0 & 4 & 0.039 \\
\hline HLA-A*02 & 7 & 17 & 2 & 12 & 38 & 0.369 \\
\hline HLA-A*03 & 2 & 1 & 0 & 0 & 3 & 0.029 \\
\hline HLA-A*11 & 0 & 0 & 0 & 2 & 2 & 0.019 \\
\hline HLA-A*23 & 0 & 0 & 1 & 0 & 1 & 0.010 \\
\hline HLA-A*24 & 4 & 4 & 1 & 0 & 9 & 0.087 \\
\hline HLA-A*25 & 0 & 1 & 0 & 0 & 1 & 0.010 \\
\hline $\mathrm{HLA}-\mathrm{A}^{*} 26$ & 0 & 1 & 0 & 0 & 1 & 0.010 \\
\hline HLA-A*29 & 2 & 0 & 0 & 4 & 6 & 0.058 \\
\hline HLA-A*31 & 1 & 5 & 4 & 7 & 17 & 0.165 \\
\hline HLA-A*32 & 0 & 0 & 2 & 0 & 2 & 0.019 \\
\hline HLA-A*33 & 1 & 3 & 1 & 6 & 11 & 0.107 \\
\hline HLA-A*68 & 3 & 1 & 2 & 0 & 6 & 0.058 \\
\hline HLA-A*69 & 1 & 1 & 0 & 0 & 2 & 0.019 \\
\hline Overall & 25 & 34 & 13 & 31 & 103 & 1 \\
\hline
\end{tabular}

NII non infected individual, AC Asymptomatic Carrier, ATLL Adult T cell leukemia/lymphoma, HAM HTLV-1- associated myelopathy

\section{Discussion}

It has been proposed that the HTLVs have arisen as a consequence of inter-species transmissions that took place millions of years ago in Africa and that HTLV-1 was introduced in America during the multiple preColumbian Mongoloid migrations over the Bering Strait, and in the post-Columbian era from Japan and with the slave trade from Africa. Therefore, the different migration waves of infected populations resulted in an ethnic/ geographical restriction in the American continent for HTLV-1 and 2. Moreover, Lou et al. described certain polymorphisms as possibly associated to susceptibility for HTLV-1 infection for ethnically related populations of Russia (HLA-A*02, A*24) and Japan (HLA-A*24 
Table 4 Number and frequency of every HLA-B allele found in our population for each group

\begin{tabular}{|c|c|c|c|c|c|c|}
\hline \multirow[t]{2}{*}{ B } & \multicolumn{4}{|c|}{ Population } & \multirow[t]{2}{*}{ Overall } & \multirow[t]{2}{*}{ Allele frequency } \\
\hline & NII & $A C$ & ATLL & HAM & & \\
\hline HLA-B*07 & 1 & 2 & 0 & 0 & 3 & 0.027 \\
\hline HLA-B*08 & 2 & 2 & 0 & 3 & 7 & 0.063 \\
\hline HLA-B*13 & 0 & 0 & 0 & 1 & 1 & 0.009 \\
\hline HLA-B*14 & 2 & 2 & 1 & 2 & 7 & 0.063 \\
\hline HLA-B*15 & 0 & 0 & 0 & 2 & 2 & 0.018 \\
\hline HLA-B*18 & 0 & 0 & 2 & 0 & 2 & 0.018 \\
\hline HLA-B*27 & 2 & 0 & 0 & 0 & 2 & 0.018 \\
\hline HLA-B*35 & 8 & 2 & 3 & 15 & 28 & 0.25 \\
\hline HLA-B*38 & 4 & 4 & 0 & 0 & 8 & 0.071 \\
\hline HLA-B*39 & 5 & 4 & 4 & 2 & 15 & 0.134 \\
\hline HLA-B*40 & 2 & 0 & 0 & 0 & 2 & 0.018 \\
\hline HLA-B*41 & 0 & 0 & 0 & 1 & 1 & 0.009 \\
\hline HLA-B*44 & 0 & 2 & 1 & 1 & 4 & 0.036 \\
\hline HLA-B*48 & 0 & 8 & 0 & 0 & 8 & 0.071 \\
\hline HLA-B*49 & 0 & 0 & 0 & 1 & 1 & 0.009 \\
\hline HLA-B*51 & 0 & 3 & 2 & 5 & 10 & 0.089 \\
\hline HLA-B*52 & 0 & 2 & 0 & 2 & 4 & 0.036 \\
\hline HLA-B*53 & 0 & 6 & 0 & 0 & 6 & 0.054 \\
\hline HLA-B*55 & 0 & 0 & 0 & 1 & 1 & 0.009 \\
\hline Overall & 26 & 37 & 13 & 36 & 112 & 1 \\
\hline
\end{tabular}

NII non infected individual, AC Asymptomatic Carrier, ATLL Adult T cell leukemia/lymphoma, HAM HTLV-1- associated myelopathy

Table 5 Number and frequency of every HLA-C allele found in our population for each group

\begin{tabular}{|c|c|c|c|c|c|c|}
\hline \multirow[t]{2}{*}{ Allele } & \multicolumn{4}{|c|}{ Population } & \multirow[t]{2}{*}{ Overall } & \multirow[t]{2}{*}{ Allele frequency } \\
\hline & $\mathrm{NII}$ & $A C$ & ATLL & HAM & & \\
\hline $\mathrm{HLA}-\mathrm{C}^{*} 01$ & 1 & 0 & 0 & 0 & 1 & 0.014 \\
\hline HLA-C ${ }^{*} 03$ & 10 & 4 & 0 & 4 & 18 & 0.243 \\
\hline $\mathrm{HLA}-\mathrm{C}^{*} 04$ & 1 & 6 & 0 & 0 & 7 & 0.095 \\
\hline HLA-C ${ }^{*} 05$ & 0 & 2 & 0 & 0 & 2 & 0.027 \\
\hline $\mathrm{HLA}-\mathrm{C}^{*} 06$ & 0 & 2 & 0 & 0 & 2 & 0.027 \\
\hline $\mathrm{HLA}-\mathrm{C}^{*} 07$ & 12 & 7 & 4 & 2 & 25 & 0.338 \\
\hline HLA-C ${ }^{*} 12$ & 2 & 1 & 0 & 0 & 3 & 0.041 \\
\hline HLA-C*15 & 0 & 8 & 2 & 0 & 10 & 0.135 \\
\hline HLA-C ${ }^{*} 16$ & 0 & 3 & 0 & 0 & 3 & 0.041 \\
\hline HLA-C ${ }^{*} 18$ & 0 & 2 & 0 & 0 & 2 & 0.027 \\
\hline HLA-C*31 & 1 & 0 & 0 & 0 & 1 & 0.014 \\
\hline Overall & 27 & 35 & 6 & 6 & 74 & 1 \\
\hline
\end{tabular}

NII non infected individual, AC Asymptomatic Carrier, ATLL Adult T cell leukemia/lymphoma, HAM HTLV-1- associated myelopathy

and $A * 26)[15,34]$. In the general population of Argentina the reported frequencies of $A * 02, A * 24$ and $A * 26$ were $24.95 \%, 11.25 \%$ and $4.02 \%$, respectively [35]. In the studied population (Table 3,4 and 5) there was a high frequency of allele $\mathrm{A}^{*} 02$ (36.89\%), and following the tendency of the data reported in the general population, the frequencies of $\mathrm{A}^{*} 24(8.74 \%), \mathrm{A}^{*} 26(0.97 \%)$ were lower. When comparing the group of NII against HTLV-1 ${ }^{+}$ individuals, there were no significant differences between them, therefore a bigger sample size could determine if there is an association regarding their frequency and HTLV-1 infection status. In the case of HLA-B and -C, 


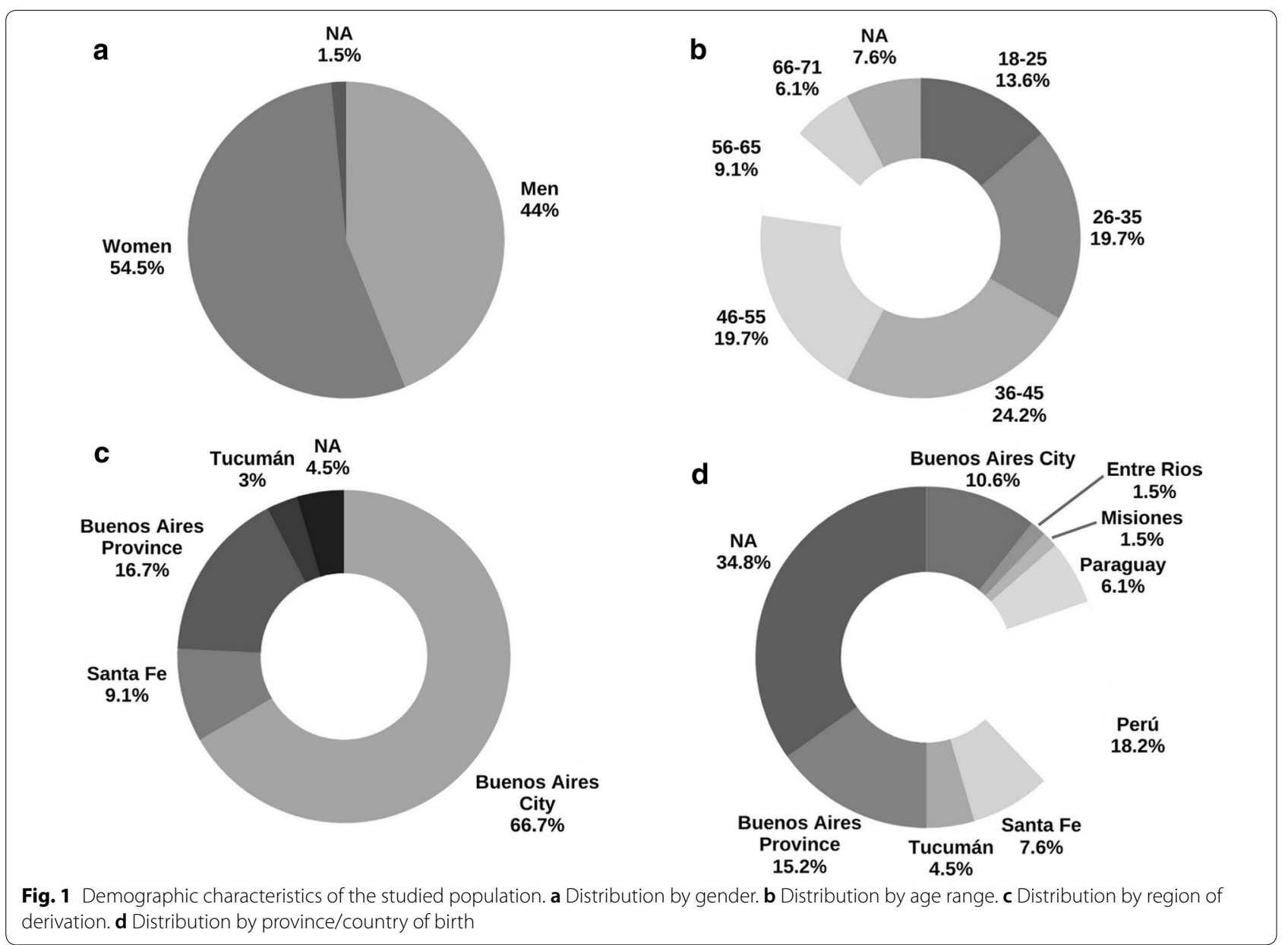

the most common alleles in Argentina are B*35 (14.6\%), $B^{*} 44(11.4 \%)$ and $B * 51$ (7.9\%), and $C * 07$ (24.6\%), C*04 (16.6\%) and $C^{*} 03$ (10.4\%) (35). Our own population largely matched these data, except for the cases of alleles $B * 44$ and $C * 04$, which were relatively uncommon $(3.6 \%$ and $9.5 \%$, respectively). B*44 was only present in HTLV-1 individuals while for $C^{*} 04$ no significant differences were found when comparing non-infected individuals vs $H T L V-1$ patients $(\mathrm{p}=0.097)$. Instead, alleles $\mathrm{B} * 39$ (13.4\%), C*03 (24.3\%) and $C^{*} 15$ (13.5\%) were among the top found. It should be noted that all the alleles are present in a lower proportion in the general population than in our own due to the fact that there was a smaller variety of alleles found in the latter, which translates in a bigger proportion of the total distribution for each of them.

Regarding, the thirteen Peruvian and the four Paraguayan individuals sampled, the allele frequencies matched the reported prevalence in these populations $[36,37]$. The most frequent alleles for HLA-A in the general population in Peru were $A * 02, A^{*} 24$ and $A^{*} 68$, in decreasing order, which correlated with our own findings. The same happened for HLA-B (most frequent
HLA-B*35), and HLA-C, the most common allele being $\mathrm{Cw}^{*} 04$. In our own population, we found 7 copies of said allele, 4 of which corresponded to Peruvian individuals. When it came to the four Paraguayan individuals tested, the most common alleles were HLA-A*02 and HLA$B * 35$, the same as for the general population in that country, although for the case of the indigenous Guaraní, the most common HLA-B alleles were HLA-B*15 and B*40. Nevertheless, when repeating the analysis taking in consideration the Argentine individuals only $(n=50)$, for HLA-A*02 the difference between AC and ATLL is still conserved $(p=0.025)$ in concordance to reports that associated this allele to protection against developing HTLV-1 associated pathologies. For HLA-B*35, we found no $\mathrm{AC}$ individuals that carried the allele, which indicates an even stronger correlation between this allele and susceptibility to HAM/TSP. HLA-C ${ }^{*} 07$, nonetheless, was no longer correlated to susceptibility to ATLL when excluding non-Argentine individuals.

Regarding the pathologies associated to HTLV-1 infection, it is known that most individuals remain asymptomatic throughout their lives. ATLL and HAM/ 


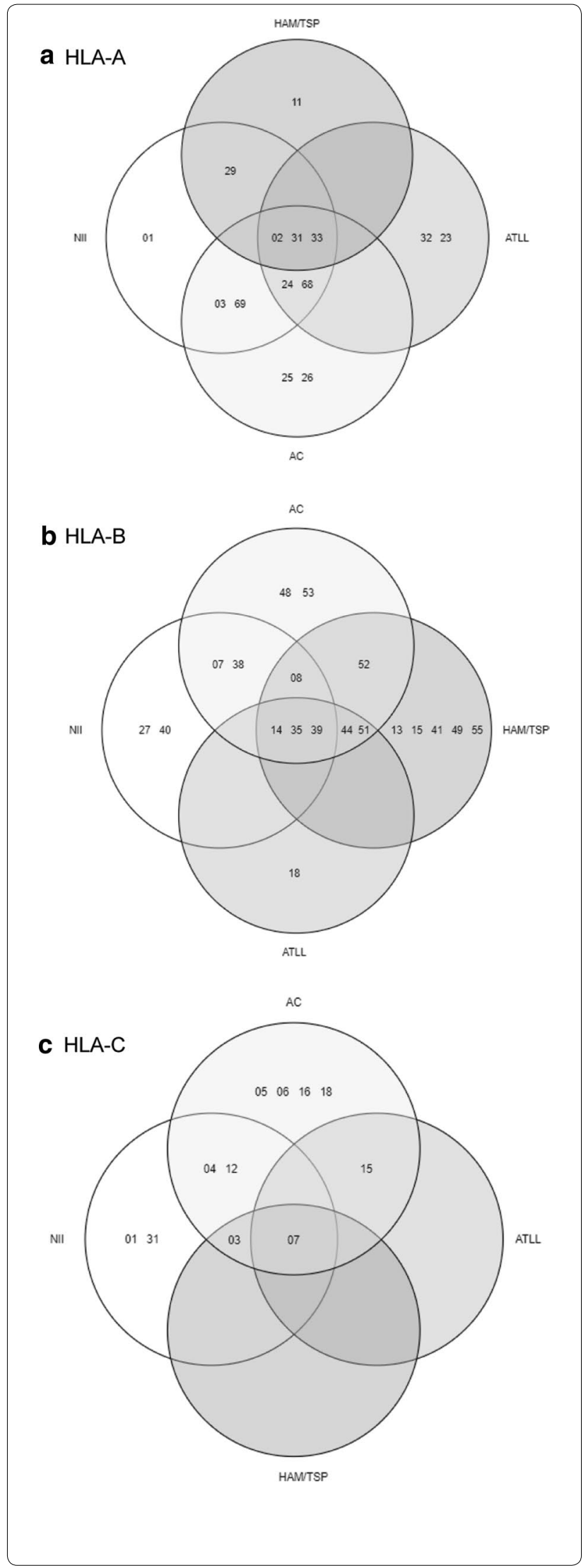

Fig. 2 Allele distribution in the different subgroups. a Distribution of HLA-A in the 4 subgroups: non-infected individuals (NII), HTLV-1 asymptomatic carriers (AC), patients with Adult T-cell leukemia/ lymphoma (ATLL) and patients with HTLV-1 associated myelopathy/ Tropical Spastic Paraparesis (HAM/TSP). b Distribution of HLA-B in the 4 subgroups: NII, AC, ATLL and HAM/TSP. c Distribution of HLA-C in the 4 subgroups: NII, AC, ATLL and HAM/TSP

TSP patients are more frequent in areas of high endemicity and they represent a small percentage of the infected population (up to $5 \%$ ).

The reasons behind the development of pathologies during adulthood and their association to host genetic factors are still unclear even though many hypotheses have been proposed. HLA class I genes may have an effect on the progression towards ATLL and HAM/TSP due to its critical role in antigen presentation [15]. Various alleles have been described as either protective or susceptible for the development of ATLL or HAM/TSP. In Jamaica, Japan and Brazil the allele HLA-A*02 has been described as protective both for ATLL and HAM/ TSP, in accordance with other studies which reported finding it significantly more frequent in asymptomatic carriers $[15,19,34]$. In our population, $A * 02$ was significantly rarer in ATLL patients when compared to HTLV $-1^{+}$asymptomatic carriers, suggesting as well a protective role for this allele in this group. This protective role could not be confirmed for HAM/TSP patients in this study. The allele HLA-A*03, previously

Table 6 Proviral load for each HLA-A allele and clinical status

\begin{tabular}{|c|c|c|c|c|}
\hline \multirow[t]{2}{*}{ Allele } & \multicolumn{3}{|c|}{ Population } & \multirow[t]{2}{*}{ Mean PVL } \\
\hline & $\overline{A C}$ & ATLL & HAM & \\
\hline HLA-A*02 & 1.42 & $12.49^{*}$ & 4.35 & 3.13 \\
\hline HLA-A*03 & $4.61^{*}$ & - & - & 4.61 \\
\hline HLA-A*11 & - & - & $4.03^{*}$ & 4.03 \\
\hline HLA-A*23 & - & $0.34^{*}$ & - & 0.34 \\
\hline HLA-A*24 & 6.64 & $0.34^{*}$ & - & 4.54 \\
\hline HLA-A*25 & $1.29^{*}$ & - & - & 1.29 \\
\hline HLA-A*26 & $1.29^{*}$ & - & - & 1.29 \\
\hline HLA-A*29 & - & - & $9.32^{* *}$ & 9.32 \\
\hline HLA-A*31 & 1.29 & 33.98 & 15.1 & 12.28 \\
\hline HLA-A*32 & - & $9.82^{*}$ & - & 9.82 \\
\hline HLA-A*33 & $1.85^{* *}$ & $40.2^{*}$ & 11.12 & 12.88 \\
\hline HLA-A*68 & $4.61^{*}$ & $1.3^{*}$ & - & 2.95 \\
\hline HLA-A*69 & ND & - & - & ND \\
\hline
\end{tabular}

AC asymptomatics carriers, HAM HTLV-1 associated myelopathy, ATLL Adult T cell leukemia/lymphoma, NII Non-infected Individuals, HLA Human leukocyte antigen, $P V L$ proviral load

* Only the PVL of one allele was available, ${ }^{* *}$ Mean PVL of two alleles 
Table 7 Proviral load for each HLA-B allele and clinical status

\begin{tabular}{lccll}
\hline Allele & \multicolumn{2}{l}{ Population } & & Mean PVL \\
\cline { 2 - 4 } & AC & ATLL & HAM & \\
\hline HLA-B*07 & $11.83^{*}$ & - & - & 11.83 \\
HLA-B*08 & $0.39^{*}$ & - & 15.12 & 10.21 \\
HLA-B*13 & - & - & $35.1^{*}$ & 35.1 \\
HLA-B*14 & $5.3^{*}$ & $1.3^{*}$ & $3.58^{* *}$ & 3.44 \\
HLA-B*15 & - & - & $3.07^{* *}$ & 3.07 \\
HLA-B*18 & - & $0.82^{* *}$ & - & 0.81 \\
HLA-B*35 & - & $5.1^{* *}$ & 6.44 & 6.12 \\
HLA-B*38 & $2.1^{* *}$ & - & - & 2.1 \\
HLA-B*39 & 0.24 & 18.78 & 7.84 & 10.36 \\
HLA-B*41 & - & - & ND & ND \\
HLA-B*44 & $0.58^{*}$ & $33.98^{*}$ & $29.54^{*}$ & 21.36 \\
HLA-B*48 & 1.24 & - & - & 1.24 \\
HLA-B*49 & - & - & $35.1^{*}$ & 35.1 \\
HLA-B*51 & 0.74 & $12.49^{*}$ & 3.7 & 4.11 \\
HLA-B*52 & $0.57^{*}$ & - & $9.32^{* *}$ & 6.41 \\
HLA-B*53 & 3.42 & - & - & 3.42 \\
HLA-B*55 & - & - & $4.03^{*}$ & 4.03 \\
\hline HCas & & & &
\end{tabular}

AC asymptomatics carriers, HAM HTLV-1 associated myelopathy, ATLL Adult T cell leukemia/lymphoma, NII Non-infected Individuals, HLA Human leukocyte antigen, $P V L$ proviral load

* Only the PVL of one allele was available, ${ }^{* *}$ Mean PVL of two alleles
Table 8 Proviral load for each HLA-C allele and clinical status

\begin{tabular}{llcll}
\hline Allele & \multicolumn{2}{l}{ Population } & \multicolumn{2}{l}{ Mean PVL } \\
\cline { 2 - 4 } & AC & ATLL & HAM & \\
\hline HLA-C*03 & $2.7^{* *}$ & - & $1.675^{* *}$ & 2.19 \\
HLA-C*04 & 0.47 & - & - & 0.47 \\
HLA-C*05 & $0.11^{*}$ & - & - & 0.11 \\
HLA-C*06 & $0.92^{*}$ & - & - & 0.92 \\
HLA-C*07 & 1.69 & $40.2^{*}$ & $4.03^{*}$ & 8.5 \\
HLA-C*12 & $0.58^{*}$ & - & - & 0.58 \\
HLA-C*15 & 1.89 & $9.87^{*}$ & - & 3.49 \\
HLA-C*16 & $2.94^{* *}$ & - & - & 2.94 \\
HLA-C*18 & $0.39^{*}$ & - & - & 0.39
\end{tabular}

AC asymptomatics carriers, HAM HTLV-1 associated myelopathy, ATLL Adult T cell leukemia/lymphoma, NII Non-infected Individuals, HLA Human leukocyte antigen, $P V L$ proviral load

* Only the PVL of one allele was available, **Mean PVL of two alleles

Table 9 Number of homozygous patients for each gene

\begin{tabular}{llll}
\hline Population & HLA-A & HLA-B & HLA-C \\
\hline NII & $10 / 12$ & $11 / 12$ & $11 / 13$ \\
AC & $12 / 17$ & $18 / 18$ & $15 / 17$ \\
ATLL & $5 / 6$ & $0 / 6$ & $3 / 3$ \\
HAM & $15 / 15$ & $4 / 15$ & $3 / 3$ \\
Overall & $42 / 50$ & $33 / 51$ & $32 / 36$ \\
\hline
\end{tabular}

$(p=0.017)$ and not to HAM/TSP $(\mathrm{p}=0.466)[16,25]$. None of the individuals with pathologies presented HLAC*07 and HLA-A*02 concomitantly, and only one out of four $\mathrm{AC}$ had them both; therefore, we could not find the protective effect of HLA-A*02 from HLA-C 07 .

Another aspect to be considered is that all of the alleles found solely in one group had a very low frequency; many of them were actually identified that one time (Table 2). They were also very rare alleles for the general Argentine population [35]. Thus, it is not possible to draw any conclusions regarding these findings. The only exceptions were HLA-B*48 and HLA-B*53, which had a frequency of $7.14 \%(8 / 112)$ and $5.36 \%(6 / 112)$ (Table 4$)$, respectively and were found solely in AC.

Many biomarkers have been proposed as prognostic for development of either ATLL (PD-1/PD-L1, absence of CD7 in $\mathrm{CD}^{+} \mathrm{T}$ cells [41-43] or HAM (CXCL10, CXCL9, neopterin and HTLV-1 antibody titers in CSF, and gender [44-46], although the most studied is PVL.

To this day, the therapies for HTLV-1 associated pathologies seek to reduce the proviral load. In the last decade, a real time quantitative PCR (qPCR) has been 
implemented for the quantification of proviral load (PVL) of HTLV-1/2 from cells of infected patients. Its determination is used as an indicator of the course of infection in asymptomatic carries in order to evaluate their predisposition to the development of pathology and to monitor treatment progression in ATLL and HAM patients [47]. It has been reported that, although the PVL has been suggested to be directly related to the severity of the disease, the values among infected individuals often vary significantly [48]. This corresponds with the dispersion of the values observed in this study. Previously reported values indicate that in asymptomatic carriers, the mean proviral load is $0.1-1$ copy/100 PBMCs, while in patients with HAM/TSP is $5-10 / 100$ PBMCs, exceeding sometimes 30 copies [48]. Despite these differences observed in the PVL values and the technique used, all the reports conclude that there is a significant difference among asymptomatics and patients with pathologies as observed in our studied population. These results also indicate that there is a correlation towards disease progression [33].

Some studies have proposed that HLA allelic variants could determine the PVL levels of HTLV-1 infected individuals $[14,49]$. Nonetheless, we couldn't find any significant differences in the PVL of any allele to support these previous claims (Tables 6, 7 and 8 ).

It has been proposed that heterozygosis on HLA confers advantages on disease progression in AIDS, revealing a greater variety of the immune response [50,51]. In accordance to this, heterozygosis for HLA-A was significantly more frequent among asymptomatics when compared to individuals with pathologies. However, the opposite was true for HLA-B, for which homozygosis was more frequent in asymptomatic carriers than in patients with pathologies (Table 9).

In conclusion, several HLA alleles identified in our study were associated with disease progression. Our results add more evidence to the protective effect of HLA-A*02 allele on progression to ATLL, and draws attention to HLA-B*35 as a new allele to be considered in relation to susceptibility to HAM/TSP, and also HLAC*07 in relation to progression to ATLL.

To this day, however, no allele or allele pattern has been identified to be exclusive to either asymptomatic individuals or those who develop pathologies, and to thus be of use when it comes to providing a predictive diagnosis. Were an allele like this to be found, in line with the rapidly evolving field of precision medicine, it would mean the possibility to conduct a closer follow up of each asymptomatic $\mathrm{HTLV}-1^{+}$carrier, for those patients that choose to learn the impact of their genetic background on the infection by HTLV-1.

\section{Conclusions}

We have found HLA-A*02, HLA-B*35 and HLA-C*07 to be associated to protection from ATLL (HLA-A*02) and susceptibility to HAM/TSP (HLA-B*35) or to ATLL (HLA-C*07), respectively. Whereas HLA-A*02 protection from ATLL has already been extensively described in other regions of the world, this is the first report that links HLA-B*35 and an increased susceptibility to HAM/ TSP. As for HLA-C*07 it has previously been associated to susceptibility to HAM/TSP in other countries but in our population it has been linked to ATLL.

These alleles could be of relevance, among other markers, to determine a model for disease development prognosis and helping the generation of a vaccine for use in different geographical areas around the world.

\section{Abbreviations}

Ac: Asymptomatic carriers; AIDS: Acquired Immunodeficiency Syndrome; ANOVA: Analysis of Variance; CONICET: Consejo Nacional de Investigaciones Científicas y Técnicas; CNS: Central Nervous System; CTL: Cytotoxic T Lymphocyte; EDTA: Ethylenediaminetetraacetic Acid; ELISA: Enzyme-Linked Immunosorbent Assay; EM: Expectation-Maximization; DNA: Desoxyribonucleic Acid; HAM/TSP: HTLV-1 Associated Myelopathy/Tropical Spastic Paraparesis; HBV: Hepatitis B Virus; HBZ: HTLV-1 basic leucine zipper factor; HIV-1: Human Immunodeficiency Virus type 1; HLA: Human Leukocyte Antigen; HTLV-1: Human T lymphotropic virus type 1; IFNY: Interferon gamma; ITAPS: International Traineeships in AIDS Prevention Studies; n-PCR: Nested Polymerase Chain Reaction; $\mathrm{NIH}$ : National Institute of Health; NII: Non-Infected Individuals; PVL: Proviral Load; PBMC: Peripheral Blood Mononuclear Cells; SBT: Sequence-Based Typing; TNF: Tumor Necrosis Factor.

\section{Acknowledgements}

We would like to thank BIOARS for their constant support by donating the ELISA kits for HTLV-1/2 diagnosis. We would also like to thank Mirta Villa, Fernando Montesano and Ricardo Casime for their devotion to attending our patients. We wish to acknowledge support through the University of California San Francisco from the following grants from the U.S. National Institutes of Health (NIH): University of California, San Francisco's International Traineeships in AIDS Prevention Studies (ITAPS), U.S. NIMH, R25MH064712 and the Starr Foundation Scholarship Fund.

\section{Authors' contributions}

PB: Data collection and curation, methodology, writing, editing. SAF: Data collection, methodology, validation, reviewing. ND: Data analysis, validation, reviewing. KP: Consultation, counselling, reviewing, funding acquisition. CB: Conceptualization, Supervision, funding acquisition. MB: Conceptualization Supervision, funding acquisition. All authors read and approved the final manuscript.

\section{Funding}

This study was supported by CONICET (PIP 112 20110100644) and FONCYT (PICT 2016 1033). And grants from the U.S. National Institutes of Health (NIH): University of California, San Francisco's International Traineeships in AIDS Prevention Studies (ITAPS), U.S. NIMH, R25MH064712 and the Starr Foundation Scholarship Fund.

\section{Availability of data and materials}

The datasets used and/or analyzed during the current study are available from the corresponding author on reasonable request.

Ethics approval and consent to participate

This study was approved by External Ethical Committee Nexo Asociación Civil IRB \#0005349, protocol \#1563. Every participant signed a written consent before donating a blood sample for analysis. 


\section{Consent for publication}

Not applicable.

\section{Competing interests}

The authors declare that they have no competing interests.

\section{Author details}

${ }^{1}$ CONICET- Universidad de Buenos Aires, Instituto de Investigaciones Biomédicas en Retrovirus y SIDA (INBIRS), Paraguay 2155, C1121ABG Ciudad Autónoma de Buenos Aires, Argentina. ${ }^{2}$ Department of Epidemiology and Biostatistics, University of California San Francisco, San Francisco, CA, USA. ${ }^{3}$ Present Address: The University of New Mexico, Internal Medicine, University of New Mexico, Albuquerque, NM, USA.

\section{Received: 21 May 2020 Accepted: 19 August 2020}

Published online: 03 September 2020

\section{References}

1. Uchiyama T, Yodoi J, Sagawa K, Takatsuki K, Uchino H. Adult T-cell leukemia: clinical and hematologic features of 16 cases. Blood. 1977;50(3):481-92.

2. Gessain A, Barin F, Vernant JC, Gout O, Maurs L, Calender A, et al. Antibodies to human T-lymphotropic virus type-l in patients with tropical spastic paraparesis. Lancet. 1985;2(8452):407-10.

3. Einsiedel L, Spelman T, Goeman E, Cassar O, Arundell M, Gessain A. Clinical associations of Human T-Lymphotropic virus type 1 infection in an indigenous Australian population. PLoS Negl Trop Dis. 2014;8(1):e2643.

4. Biglione MM, Astarloa L, Salomón HE, Referent HTLV-I/II Argentina Group. High prevalence of HTLV-I and HTLV-II among blood donors in Argentina: a South American health concern. AIDS Res Hum Retroviruses. 2005;21(1):1-4.

5. Kaplan JE, Osame M, Kubota H, Igata A, Nishitani H, Maeda Y, et al. The risk of development of HTLV-I-Associated Myelopathy/Tropical Spastic Paraparesis among persons infected with HTLV-I. J Acquir Immune Defic Syndr. 1990;3(11):1096-101.

6. Johnson JM, Harrod R, Franchini G. Molecular biology and pathogenesis of the human T-cell leukaemia/lymphotropic virus Type-1 (HTLV-1). Int J Exp Pathol. 2001;82(3):135-47.

7. Futsch N, Mahieux R, Dutartre H. HTLV-1, the other pathogenic yet neglected human retrovirus: from transmission to therapeutic treatment. Viruses. 2017;10(1):1.

8. Satou Y, Yasunaga J-I, Zhao T, Yoshida M, Miyazato P, Takai K, et al. HTLV-1 bZIP factor induces T-cell lymphoma and systemic inflammation in vivo. PLoS Pathog. 2011;7(2):e1001274.

9. Bangham CRM, Osame M. Cellular immune response to HTLV-1. Oncogene. 2005;24(39):6035-46.

10. Enose-Akahata Y, Jacobson S. Immunovirological markers in HTLV-1-associated myelopathy/tropical spastic paraparesis (HAM/TSP). Retrovirology. 2019;16(1):35

11. Best I, Adaui V, Verdonck K, González E, Tipismana M, Clark D, et al. Proviral load and immune markers associated with human T-lymphotropic virus type 1 (HTLV-1)-associated myelopathy/tropical spastic paraparesis (HAM/TSP) in Peru. Clin Exp Immunol. 2006;146(2):226-33.

12. da Silva Dias GA, Sousa RCM, Gomes LF, Caldas CAM, Nassiri R, Quaresma JAS, et al. Correlation between clinical symptoms and peripheral immune response in HAM/TSP. Microb Pathog. 2016;92:72-5.

13. Sonoda S, Li HC, Tajima K. Ethnoepidemiology of HTLV-1 related diseases: ethnic determinants of HTLV-1 susceptibility and its worldwide dispersal. Cancer Sci. 2011;102(2):295-301.

14. Treviño A, Vicario JL, Lopez M, Parra P, Benito R, de Ortiz Lejarazu R, et al. Association between HLA alleles and HAM/TSP in individuals infected with HTLV-1. J Neurol. 2013;260(10):2551-5.

15. Jeffery KJ, Siddiqui AA, Bunce M, Lloyd AL, Vine AM, Witkover AD, et al The influence of HLA class I alleles and heterozygosity on the outcome of human T cell lymphotropic virus type I infection. J Immunol. 2000;165(12):7278-84

16. Jeffery KJ, Usuku K, Hall SE, Matsumoto W, Taylor GP, Procter J, et al. HLA alleles determine human T-lymphotropic virus-I (HTLV-I) proviral load and the risk of HTLV-I-associated myelopathy. Proc Natl Acad Sci USA. 1999;96(7):3848-53.

17. White JD, Johnson JA, Nam JM, Cranston B, Hanchard B, Waldmann TA, et al. Distribution of human leukocyte antigens in a population of black patients with human T-cell lymphotrophic virus type I-associated adult T-cell leukemia/lymphoma. Cancer Epidemiol Biomarkers Prev. 1996;5(11):873-7.

18. Borducchi DM, Gerbase-DeLima M, Morgun A, Shulzhenko N, Pombo-deOliveira MS, Kerbauy J, et al. Human leucocyte antigen and human T-cell lymphotropic virus type 1 associated diseases in Brazil. Br J Haematol. 2003;123(5):954-5.

19. Coelho-dos-Reis JGA, Rocha RDR, Brito-Melo GEA, Ribas JG, de CarneiroProietti ABF, Catalan-Soares B, et al. Evaluation of the performance of immunological parameters as indicators for clinical progression of chronic HTLV-1 infection. Rev Soc Bras Med Trop. 2007;40(1):29-36.

20. Macnamara A, Rowan A, Hilburn S, Kadolsky U, Fujiwara H, Suemori K, et al. HLA class I binding of HBZ determines outcome in HTLV-1 infection. PLoS Pathog. 2010;6(9):e1001117.

21. Talledo M, López G, Huyghe JR, Verdonck K, Adaui V, González E, et al. Evaluation of host genetic and viral factors as surrogate markers for HTLV-1-associated myelopathy/tropical spastic paraparesis in Peruvian HTLV-1-infected patients. J Med Virol. 2010;82(3):460-6.

22. Rafatpanah H, Pravica V, Faridhosseini R, Tabatabaei A, Ollier W, Poulton $K$, et al. Association between HLA-DRB ${ }^{*} 01$ and $\mathrm{HLA}-\mathrm{CW}^{*} 08$ and outcome following HTLV-I infection. Iran J Immunol. 2007;4(2):94-100.

23. Yashiki $S$, Fujiyoshi T, Arima N, Osame $M$, Yoshinaga $M$, Nagata $Y$, et al. HLA-A*26, HLA-B*4002, HLA-B*4006, and HLA-B*4801 alleles predispose to adult T cell leukemia: the limited recognition of HTLV type 1 tax peptide anchor motifs and epitopes to generate anti-HTLV type 1 tax CD8(+) cytotoxic T lymphocytes. AIDS Res Hum Retroviruses. 2001;17(11):1047-61.

24. Sabouri AH, Saito M, Usuku K, Bajestan SN, Mahmoudi M, Forughipour M, et al. Differences in viral and host genetic risk factors for development of human T-cell lymphotropic virus type 1 (HTLV-1)-associated myelopathy/ tropical spastic paraparesis between Iranian and Japanese HTLV-1-infected individuals. J Gen Virol. 2005;86(Pt 3):773-81.

25. Catalan-Soares BC, Carneiro-Proietti ABF, Da Fonseca FG, Correa-Oliveira R, Peralva-Lima D, Portela R, et al. HLA class I alleles in HTLV-1-associated myelopathy and asymptomatic carriers from the Brazilian cohort GIPH. Med Microbiol Immunol. 2009;198(1):1-3.

26. Carrington M, O'Brien SJ. The influence of HLA genotype on AIDS. Annu Rev Med. 2003;54:535-51.

27. Trachtenberg E, Korber B, Sollars C, Kepler TB, Hraber PT, Hayes E, et al. Advantage of rare HLA supertype in HIV disease progression. Nat Med. 2003;9(7):928-35

28. Goedert JJ, Li H-C, Gao X-J, Chatterjee N, Sonoda S, Biggar RJ, et al. Risk of human T-lymphotropic virus type I-associated diseases in Jamaica with common HLA types. Int J Cancer. 2007;121(5):1092-7.

29. Tsukasaki K, Hermine O, Bazarbachi A, Ratner L, Ramos JC, Harrington W, et al. Definition, prognostic factors, treatment, and response criteria of adult T-cell leukemia-lymphoma: a proposal from an international consensus meeting. J Clin Oncol. 2009;27(3):453-9.

30. Heneine W, Khabbaz RF, Lal RB, Kaplan JE. Sensitive and specific polymerase chain reaction assays for diagnosis of human T-cell lymphotropic virus type I (HTLV-I) and HTLV-II infections in HTLV-I/II-seropositive individuals. J Clin Microbiol. 1992;30(6):1605-7.

31. Cánepa C, Salido J, Ruggieri M, Fraile S, Pataccini G, Berini C, et al. Low proviral load is associated with indeterminate western blot patterns in human T-cell lymphotropic virus type 1 infected individuals: could punctual mutations be related? Viruses. 2015;7(11):5643-58.

32. Altamirano NA, Rocco C, Aulicino P, Sen L, Mangano A. Quantitation of HTLV-I proviral load by a real-time PCR assay using SYBR Green: comparison of two methods for DNA isolation. J Virol Methods. 2010;170(1-2):160-4.

33. Cereb N, Maye P, Lee S, Kong Y, Yang SY. Locus-specific amplification of HLA class I genes from genomic DNA: locus-specific sequences in the first and third introns of HLA-A, $-B$, and $-C$ alleles. Tissue Antigens. 1995:45(1):1-11.

34. Lou H, Li HC, Kuwayama M, Yashiki S, Fujiyoshi T, Suehara M, et al. HLA class I and class II of the Nivkhi, an indigenous population carrying HTLV-I in Sakhalin. Far Eastern Russia Tissue Antigens. 1998;52(5):444-51. 
35. Perusco A, Gamba C, Galarza P, Rojas F, Kalapodis A, Onofri A, et al. HLA antigenic and haplotype frequencies estimated in hematopoietic progenitor cell donors from Argentina. Transplant Proc. 2014;46(9):3064-7.

36. de Pablo R, Beraún Y, Nieto A, Calzada JE, Rementería MC, Sanz L, et al. HLA class I and class II allele distribution in the Peruvian population. Tissue Antigens. 2000;56(6):507-14.

37. Benitez O, Busson M, Charron D, Loiseau P. HLA polymorphism in a Guarani-Indian population from Paraguay and its usefulness for the HispanoIndian admixture study in Paraguay. Int J Immunogenet. 2011;38(1):7-11.

38. Pan N, Chen K, Qiu J, Sun H, Xu J, Miao F, et al. Human leukocyte antigen class I alleles and haplotypes associated with primary hepatocellular carcinoma in persistent HBV-infected patients. Hum Immunol. 2013;74(6):758-63.

39. Angulo JMC, Cuesta TAC, Menezes EP, Pedroso C, Brites C. A systematic review on the influence of HLA-B polymorphisms on HIV-1 mother-tochild-transmission. Braz J Infect Dis. 2019;23(1):53-9.

40. Gao X, O'Brien TR, Welzel TM, Marti D, Qi Y, Goedert JJ, et al. HLA-B alleles associate consistently with HIV heterosexual transmission, viral load, and progression to AIDS, but not susceptibility to infection. AIDS. 2010:24(12):1835-40.

41. Kozako T, Yoshimitsu M, Fujiwara H, Masamoto I, Horai S, White Y, et al. PD-1/PD-L1 expression in human T-cell leukemia virus type 1 carriers and adult T-cell leukemia/lymphoma patients. Leukemia. 2009;23(2):375-82.

42. Shimauchi T, Kabashima K, Nakashima D, Sugita K, Yamada Y, Hino R, et al. Augmented expression of programmed death-1 in both neoplastic and non-neoplastic CD4+ T-cells in adult T-cell leukemia/lymphoma. Int J Cancer. 2007:121(12):2585-90.

43. Kagdi HH, Demontis MA, Fields PA, Ramos JC, Bangham CRM, Taylor GP. Risk stratification of adult T-cell leukemia/lymphoma using immunophenotyping. Cancer Med. 2017;6(1):298-309.

44. Sato T, Coler-Reilly A, Utsunomiya A, Araya N, Yagishita N, Ando H, et al. CSF CXCL10, CXCL9, and neopterin as candidate prognostic biomarkers for HTLV-1-associated myelopathy/tropical spastic paraparesis. PLoS Negl Trop Dis. 2013;7(10):e2479.

45. Matsuura E, Nozuma S, Tashiro Y, Kubota R, Izumo S, Takashima H. HTLV-1 associated myelopathy/tropical spastic paraparesis (HAM/TSP): a comparative study to identify factors that influence disease progression. J Neurol Sci. 2016;15(371):112-6.

46. Gessain A, Mahieux R. Tropical spastic paraparesis and HTLV-1 associated myelopathy: clinical, epidemiological, virological and therapeutic aspects. Rev Neurol (Paris). 2012;168(3):257-69.

47. Montanheiro PA, de Oliveira ACP, Posada-Vergara MP, Milagres AC, Tauil C, Marchiori PE, et al. Human T-cell lymphotropic virus type I (HTLV-I) proviral DNA viral load among asymptomatic patients and patients with HTLV-I-associated myelopathy/tropical spastic paraparesis. Braz J Med Biol Res. 2005;38(11):1643-7.

48. Arriagada RC, Court LJ, Novoa SF. Tratado de neurología clínica. Rev Chil Neuro-Psiquiatr. 2005. https://doi.org/10.4067/S0717-922720050004000 12.

49. Taghaddosi M, Rezaee SAR, Rafatpanah H, Rajaei T, Farid Hosseini R, Narges V. Association between HLA class I Alleles and Proviral Load in HTLV-I Associated Myelopathy/Tropical Spastic Paraperesis (HAM/TSP) patients in Iranian population. Iran J Basic Med Sci. 2013;16(3):264-7.

50. Jacobson S, Shida H, McFarlin DE, Fauci AS, Koenig S. Circulating CD8+ cytotoxic T lymphocytes specific for HTLV-I pX in patients with HTLV-I associated neurological disease. Nature. 1990;348(6298):245-8.

51. Hurley CK, Fernandez-Vina M, Hildebrand WH, Noreen HJ, Trachtenberg E, Williams TM, et al. A high degree of HLA disparity arises from limited allelic diversity: analysis of 1775 unrelated bone marrow transplant donor-recipient pairs. Hum Immunol. 2007;68(1):30-40.

52. Manns A, Hanchard B, Morgan OS, Wilks R, Cranston B, Nam JM, et al. Human leukocyte antigen class II alleles associated with human T-cell lymphotropic virus type I infection and adult T-cell leukemia/lymphoma in a Black population. J Natl Cancer Inst. 1998;90(8):617-22.

53. Sonoda S, Fujiyoshi T, Yashiki S. Immunogenetics of HTLV-I/II and associated diseases. J Acquir Immune Defic Syndr Hum Retrovirol. 1996;13(Suppl 1):S119-S12323.

\section{Publisher's Note}

Springer Nature remains neutral with regard to jurisdictional claims in published maps and institutional affiliations.
Ready to submit your research? Choose BMC and benefit from:

- fast, convenient online submission

- thorough peer review by experienced researchers in your field

- rapid publication on acceptance

- support for research data, including large and complex data types

- gold Open Access which fosters wider collaboration and increased citations

- maximum visibility for your research: over $100 \mathrm{M}$ website views per year

At BMC, research is always in progress.

Learn more biomedcentral.com/submissions 